University of Nebraska - Lincoln

DigitalCommons@University of Nebraska - Lincoln

2012

Iterative atmospheric correction scheme and the polarization color of alpine snow

\author{
Matteo Ottaviani \\ NASA Goddard Institute for Space Studies, matteo.ottaviani@nasa.gov \\ Brian Cairns \\ NASA Goddard Institute for Space Studies \\ Rich Ferrare \\ NASA Langley Research Center \\ Raymond Rogers \\ NASA Langley Research Center
}

Follow this and additional works at: https://digitalcommons.unl.edu/nasapub

Part of the Physical Sciences and Mathematics Commons

Ottaviani, Matteo; Cairns, Brian; Ferrare, Rich; and Rogers, Raymond, "Iterative atmospheric correction scheme and the polarization color of alpine snow" (2012). NASA Publications. 76.

https://digitalcommons.unl.edu/nasapub/76

This Article is brought to you for free and open access by the National Aeronautics and Space Administration at DigitalCommons@University of Nebraska - Lincoln. It has been accepted for inclusion in NASA Publications by an authorized administrator of DigitalCommons@University of Nebraska - Lincoln. 


\title{
Iterative atmospheric correction scheme and the polarization color of alpine snow
}

\author{
Matteo Ottaviani ${ }^{\mathrm{a}, \mathrm{b}, *}$, Brian Cairns ${ }^{\mathrm{a}}$, Rich Ferrare ${ }^{\mathrm{c}}$, Raymond Rogers ${ }^{\mathrm{c}}$ \\ a NASA Goddard Institute for Space Studies, New York, NY, USA \\ ${ }^{\mathrm{b}}$ NASA Postdoctoral Program, Oak Ridge Associated Universities, Oak Ridge, TN, USA \\ ${ }^{\text {c }}$ NASA Langley Research Center, Hampton, Virginia, USA
}

\section{A R T I C L E I N F O}

\section{Article history:}

Received 6 February 2012

Received in revised form

14 March 2012

Accepted 15 March 2012

Available online 22 March 2012

\section{Keywords:}

Remote sensing

Polarization

Snow

Polarized BRDF

Tuolumne Intrusive Suite

\section{A B S T R A C T}

Characterization of the Earth's surface is crucial to remote sensing, both to map geomorphological features and because subtracting this signal is essential during retrievals of the atmospheric constituents located between the surface and the sensor. Current operational algorithms model the surface total reflectance through a weighted linear combination of a few geometry-dependent kernels, each devised to describe a particular scattering mechanism. The information content of these measurements is overwhelmed by that of instruments with polarization capabilities: proposed models in this case are based on the Fresnel reflectance of an isotropic distribution of facets. Because of its remarkable lack of spectral contrast, the polarized reflectance of land surfaces in the shortwave infrared spectral region, where atmospheric scattering is minimal, can be used to model the surface also at shorter wavelengths, where aerosol retrievals are attempted based on well-established scattering theories.

In radiative transfer simulations, straightforward separation of the surface and atmospheric contributions is not possible without approximations because of the coupling introduced by multiple reflections. Within a general inversion framework, the problem can be eliminated by linearizing the radiative transfer calculation, and making the Jacobian (i.e., the derivative expressing the sensitivity of the reflectance with respect to model parameters) available at output. We present a general methodology based on a Gauss-Newton iterative search, which automates this procedure and eliminates de facto the need of an ad hoc atmospheric correction.

In this case study we analyze the color variations in the polarized reflectance measured by the NASA Goddard Institute of Space Studies Research Scanning Polarimeter during a survey of late-season snowfields in the High Sierra. This insofar unique dataset presents challenges linked to the rugged topography associated with the alpine environment and a likely high water content due to melting. The analysis benefits from ancillary information provided by the NASA Langley High Spectral Resolution Lidar deployed on the same aircraft.

The results obtained from the iterative scheme are contrasted against the surface polarized reflectance obtained ignoring multiple reflections, via the simplistic subtraction of the atmospheric scattering contribution. Finally, the retrieved reflectance is modeled after the scattering properties of a dense collection of ice crystals at the surface. Confirming that the polarized reflectance of snow is spectrally flat would allow to extend the techniques already in use for polarimetric retrievals of aerosol properties

\footnotetext{
${ }^{*}$ Corresponding author at: NASA Goddard Institute for Space Studies, New York, NY, USA.

E-mail address: matteo.ottaviani@nasa.gov (M. Ottaviani).
} 
over land to the large portion of snow-covered pixels plaguing orbital and suborbital observations.

(c) 2012 Elsevier Ltd. All rights reserved.

\section{Introduction}

Meaningful retrievals of surface and atmospheric properties from space- or air-borne remote sensing data rely on accurate radiative transfer models as well as on successful separation of the surface and the atmospheric signals. In the case of retrievals over land, most operational algorithms currently in use model the surface contribution by decomposing the total surface reflectance $R$ in a sum of weighted kernels

$R\left(\theta_{s}, \theta_{r}, \phi, \mathbf{b}\right)=\sum_{k=1}^{K} f_{k}(\lambda) K_{k}\left(\theta_{s}, \theta_{r}, \phi, \mathbf{b}\right)$.

The kernels $K_{k}$ depend on the geometry of observation (i.e., on the solar zenith angle $\theta_{s}$, the viewing zenith angle $\theta_{r}$, and the Sun-sensor relative azimuth $\phi$ ). Following the notation of Rodgers [1], the term $\mathbf{b}$ includes all other parameters involved non-linearly, such as wavelength (via the refractive index of the underlying medium) or the aspect ratio of the scattering objects at the surface. These dependencies, as well as that of the kernel weights $f_{k}$ on the wavelength, are dropped from the notation in what follows but remain understood. Although several kernels have been proposed, a common combination is the RossThick-LiSparse form

$R=f_{\text {iso }}+f_{\text {vol }} K_{\text {vol }}+f_{\text {geo }} K_{\text {geo }}$

The first term on the right side of the equation is a Lambertian contribution with no directional dependence (i.e., kernel-free). The second term involves a kernel representing scattering within dense vegetation canopies and was derived by Roujean [2] from previous work [3]. The last, geometric kernel accounts for shadowing of a Lambertian background from objects of larger size, and dates back to the model of Li and Strahler [4], although slightly modified by Lucht et al. [5]. The functional form of these kernels can be found in the literature [6,7].

The RossThick-LiSparse combination is used in retrieval algorithms implemented for Earth-orbiting remote sensors such as the MODerate resolution Imaging Spectroradiometer (MODIS $[8,9,5]$ ) and the POLarization and Directionality of the Earth's Reflectances (POLDER [10]). The Multi-angle Imaging SpectroRadiometer (MISR) uses a different parameterization named Modified RahmanPinty-Verstraete (MRPV) model [11]. Additional Fresneltype kernels $[12,13]$ have been developed for POLDER, to this date the only spaceborne platform measuring polarization in the visible and near-infrared portion of the electromagnetic spectrum. The same kernels are also an option for modeling the data collected by the NASA Goddard Institute for Space Studies (GISS) Research Scanning Polarimeter (RSP) [14,15], the airborne prototype of the Aerosol Polarimetry Sensor (APS) which unfortunately failed to reach orbit due to a rocket underperformance at launch in 2011.

The capability of measuring polarization adds greatly to the information content of remote sensing observations, and can help to resolve ambiguities in retrievals that use intensity only both over land and over ocean [15-19]. Exploiting this type of information requires the understanding of the physical processes which can alter the essentially unpolarized state of the solar light incident at the top of the atmosphere.

The information on the linear state of polarization of an observed scene is contained in the $Q$ and $U$ components of the Stokes vector. These two unbounded quantities are always specified relative to a reference system. Single scattering properties are naturally described relative to the scattering plane, which contains the directions of the incident and the scattered beam. As a simple consequence of the form of the phase matrix [20], the $U$ component in this situation is inherently null so that the $Q$ parameter alone is sufficient to specify the polarized reflectance $R_{p}=\sqrt{Q^{2}+U^{2}}$. For an instrument like the RSP, the implicit reference system is instead the meridional (scanning) plane. Even in this case, the $Q$ parameter can be sufficient provided a rotation from the meridional into the scattering plane is first applied [21,16]. However, for airborne observations, an accurate estimate of the angle of rotation can suffer from uncertainties associated with instabilities in aircraft attitude. More importantly, the total observed signal is the sum of direct-beam and diffuse contributions: in problems involving surface reflection and multiple scattering in general a unique scattering plane for both these components cannot be defined unless the observations take place along the principal plane, defined as the plane containing the incident direct beam and the local normal to the surface. At any other viewing geometry, rotation into either reference system leaves a residual $U$ component. This contribution becomes detectable at viewing angles close to backscatter, where both molecular and surface contributions are small and important structural signatures determined by aerosol (multiple) scattering may occur. The polarized reflectance has the modeling advantage of being independent of the reference system and of preserving the information contained in the residual $U$ component. It is nevertheless a positive quantity which often exhibits discontinuous derivatives at zero (in correspondence of polarization inversions), where care must be used in the statistical interpretation of the error bars.

For most viewing geometries, the largest contribution to the polarized reflectance observed in the visible part of the electromagnetic spectrum from a downward-looking remote sensor comes from molecules and aerosols in the atmosphere. Rayleigh scattering from molecules produces light which vibrates perpendicularly to the plane of 
scattering, while aerosols can polarize light both in the parallel and the perpendicular direction. The contribution due to the Earth's surface is smaller because it originates from reflection of the diffuse downward component, unless the observation takes place close to the principal plane. In a cone centered around the specular reflection direction, the surface can in fact have an overwhelming effect because of the high polarization introduced by the reflection of the direct beam. This condition is evident for sunglint over the ocean [22-24], governed by Fresnel reflection from a collection of facets typically described by a wave slope distribution [25].

Specular reflection is also the basic mechanism governing the reflection properties of most land surfaces, a fact that has been attributed to the smooth wax coating the leaves [26,27] and to the mineral facets of bare soils [28]. In a reflection event, the Fresnel formulae predict that the component of light perpendicular to the plane of reflection always exhibits higher reflectivity than does the parallel component, in a variable amount that depends on the angle of incidence. For this reason, a specular reflector always polarizes light in a direction perpendicular to the plane of reflection, with the extreme case of $100 \%$ of polarization introduced at Brewster angle. The fractional polarized reflectance $F_{p}\left(\theta_{i}\right)$ is [29]

$F_{p}\left(\theta_{i}\right)=\frac{1}{2}\left[\left(\frac{n_{1} \cos \theta_{i}-n_{2} \cos \theta_{t}}{n_{1} \cos \theta_{i}+n_{2} \cos \theta_{t}}\right)^{2}-\left(\frac{n_{2} \cos \theta_{i}-n_{1} \cos \theta_{t}}{n_{2} \cos \theta_{i}+n_{1} \cos \theta_{t}}\right)^{2}\right]$

where the angle of refraction $\theta_{t}$ is connected to the angle of incidence $\theta_{i}$ by the Snell's law of reflection

$n_{1} \sin \theta_{i}=n_{2} \cos \theta_{t}$

and $n_{1}$ and $n_{2}$ are the indices of refraction of the two media.

Corrections to the simple Fresnel model over land account for geometric effects such as multiple reflections and self-shadowing, so that ultimately some function of the Fresnel reflectance is used. Proposed models are based on the assumption of an isotropic distribution of facets on surfaces dominated by vegetation or bare soil $[30,28,26]$ :

$R_{p}^{v e g}=\frac{F_{P}\left(\theta_{i}\right)}{4\left[\cos \left(\theta_{s}\right)+\cos \left(\theta_{v}\right)\right]}$

$R_{p}^{\text {soil }}=\frac{F_{P}\left(\theta_{i}\right)}{4 \cos \left(\theta_{s}\right) \cos \left(\theta_{v}\right)}$

The functional form for the polarized reflectance of the soil model of Eq. (6) has the disadvantage of leading to unphysical values of albedo (greater than 1) at some viewing geometries. In order to fit the surface polarized reflectance we employ the vegetation model, which instead ensures proper behavior, scaled with the weight $f_{\text {fresnel }}$ to account for variability in refractive index to which Eq. (5) is roughly proportional.

As stated above, the real part of the index of refraction of most natural surfaces varies very little across the visible and shortwave infrared spectral range [31]. This remarkable property enables the possibility to use the surface signal measured at long wavelengths, where atmospheric scattering is negligible, to model the surface contribution also at shorter wavelengths. This approach is at the heart of techniques for the retrieval of aerosol properties over land based on high-accuracy polarimetric measurements [15].

In summary, an appropriate polarized reflectance model should be able to closely mimic the surface signal with a twofold purpose: (a) to infer information on the surface characteristics such as vegetation cover [32], leaf orientation [33] and size [34], or macroscopic roughness [35]; and (b) to correct the signal when attempting to retrieve properties of the atmospheric constituents above the surface itself $[36,15]$.

This investigation tests the performance of the RossThick-LiSparse model applied to the unique surface type represented by alpine snow. The main goal, however, is to provide information on the spectral variability of the polarized reflectance of the surveyed snow surfaces over the 410-2264 $\mathrm{nm}$ range. Section 2 presents the iterative scheme used to retrieve an estimate of the surface signal, and its application to a synthetic scene. The following sections contain a description of the research flight performed over a snow target in June 2010 (Section 3), and a general summary of the optical properties of snow (Section 4). The results obtained by applying the iterative scheme to the collected dataset are contrasted with a standard atmospheric correction in Section 5. The conclusions are found in Section 6.

\section{Iterative atmospheric correction scheme}

The independent variables of the model function (2) are the $M$ values of the kernels $K_{j}$ for the particular geometry of observation $i$. If the surface reflectance $R_{s, i}$ were directly measured by the sensor, with hypothetical measurement error $\epsilon_{i}$, it could be modeled as

$R_{s, i}=\rho\left(\mathbf{f}^{\dagger}, K_{j, i}\right)+\epsilon_{i}$

or in matrix form, for $N$ viewing geometries as is the case for a scanning instrument:

$\mathbf{R}_{s}=\mathbf{K}^{T} \mathbf{f}^{\dagger}+\boldsymbol{\epsilon}$

where $\mathbf{f}^{\dagger}$ is the $M \times 1$ state vector composed of an optimal choice of the weighting parameters $f_{j}$ for each $\mathbf{K}_{j}$, now column vectors each of dimensions $N$ grouped into the $M \times N$ matrix $\mathbf{K}$. Since the model is linear in the variables $\mathbf{K}_{j}$, the solution could be found with a linear least-square regression formally expressed through normal equations

$\left(\mathbf{K}^{T} \mathbf{K}\right) \mathbf{f}^{\dagger}=\mathbf{K}^{T} \mathbf{R}_{s}$.

Each reflectance measured by the sensor is instead a certain non-linear function of the kernel coefficients. This non-linear function is represented by the entire radiative transfer model $\mathbf{F}$, and to minimize the mismatch with the observations, the residuals $\phi_{i}$

$\phi_{i}(\mathbf{f})=R_{i}-F_{i}(\mathbf{f})$

are used to calculate the scalar cost function $\Phi$ as the sum of their squares

$\Phi(\mathbf{f})=\sum_{i=1}^{N} \phi_{i}(\mathbf{f})^{2}=\phi^{T}(\mathbf{f}) \phi(\mathbf{f})$ 
The condition at minimum is

$\frac{\partial \Phi}{\partial f_{j}}=2 \sum_{i=1}^{N} \phi_{i} \frac{\partial \phi_{i}}{\partial f_{j}}=0$

and an iterative approach must be used to solve these equations. The problem, written in compact form as $\mathbf{f}^{\dagger}=\operatorname{argmin}_{\mathbf{f}}\{\Phi(\mathbf{f})\}$, may be formidable to solve when looking for an absolute minimum of the cost function. Several approaches are available when restricting the search to a local minimum within a small region $\delta$, so as to have $\Phi\left(\mathbf{f}^{\star}\right) \leq \Phi(\mathbf{f}) \forall \mathbf{f}:\left\|\mathbf{f}-\mathbf{f}^{\star}\right\|<\delta$.

Pending differentiability and good behavior of $F$ and its derivatives within the neighborhood of the current iteration state $\mathbf{f}^{k}$, we can use a Taylor expansion to write

$F_{i}(\mathbf{f}) \sim F_{i}\left(\mathbf{f}^{k}\right)+\sum_{j} J_{i, j}^{k} \delta f_{j}^{k}+O\left(\left\|\delta \mathbf{f}^{k}\right\|^{2}\right)$

where $\delta f_{j}^{k}=f_{j}-f_{j}^{k}$ and $J_{i j}^{k}$ is the Jacobian, or array of partial derivatives of $F_{i}$ with respect to each $f_{j}$. The residuals are then approximated by

$\phi_{i}^{k}\left(\mathbf{f}^{k}\right) \sim\left[R_{i}-F_{i}\left(\mathbf{f}^{k}\right)\right]-\sum_{j=1}^{M} J_{i j}^{k} \delta f_{j}^{k}$

from which we also derive $\partial \phi_{i}^{k} / \partial f_{j}^{k}=-J_{i j}^{k}$. Substituting in (12) we obtain the linear set of equations $\left[\mathbf{R}-\mathbf{F}\left(\mathbf{f}^{k}\right)\right]=\mathbf{J}^{k, T} \delta \mathbf{f}^{k}$ that can be cast in the form of normal equations as in (9):

$\left(\mathbf{J}^{k, T} \mathbf{J}^{k}\right) \delta \mathbf{f}^{k}=\mathbf{J}^{k}\left[\mathbf{R}-\mathbf{F}\left(\mathbf{f}^{k}\right)\right]$

with the difference that now the unknown is the increment $\delta \mathbf{f}^{k}$, the regressor is the departure from the model $\mathbf{R}-\mathbf{F}$ and the matrix involved in the inversion is the Jacobian. In other words, whenever a first-order Taylor expansion is a good approximation, the search for a minimum of a non-linear function can be turned into a (iterative) linear regression on its increments. The advantage of this approach becomes clear when considering that the Jacobians are a byproduct of the Doubling Adding simulations, conveniently output free

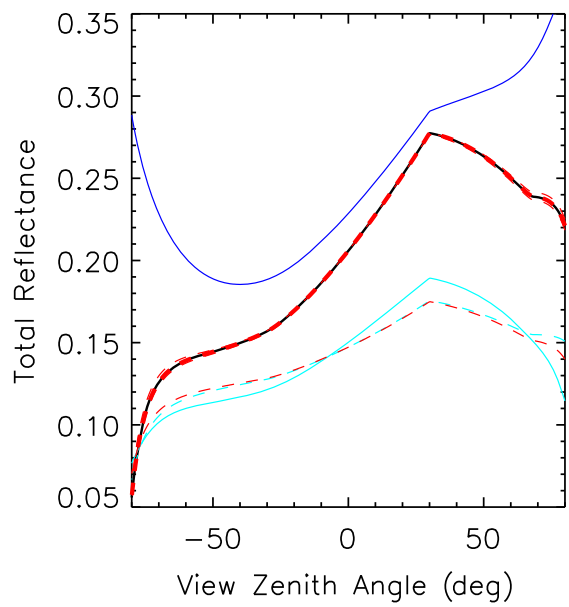

of additional computational cost. At each iteration step $k$, a better approximation to $\mathbf{f}^{\star}$ is obtained from the recursive relation $\mathbf{f}^{k+1}=\mathbf{f}^{k}+\delta \mathbf{f}^{k}$, and the model run again to obtain a new value for $\delta \mathbf{f}^{k}$. This procedure is repeated until convergence, essentially applying Gauss-Newton's method for the search of a local minimum. This method is extremely powerful and performs best with smooth functions of low curvature. The convergence is quadratic for functions that are twice differentiable in the neighborhood of a simple root, and can be reached in one iteration in the limit case of linear functions.

The concepts illustrated above are the basis for the linearization of radiative transfer codes, obtained for example for the Discrete Ordinate [37,38] and the Doubling Adding [39] formulations. Specific applications focus on trace gas retrievals [39], surface properties [40,41] and extensions from plane parallel to spherical atmospheres $[42,43]$. A few recent studies, albeit applied to total reflectance only, explore regularization of ill-conditioned inversions deriving from a limited set of viewing angles [44], a situation that highlights the advantages of multiangle measurements like those provided by the RSP.

To test its performance, the iterative method was first applied to a synthetic scene consisting of a purely Rayleigh atmosphere at $410 \mathrm{~nm}$, where scattering is significant and many of the surface features are washed out. The solar zenith angle was set at $30^{\circ}$. The surface was prepared according to the model in Eqs. (2) and (5) by choosing the following set of parameters: $\left\{f_{\text {iso }}, f_{\mathrm{vol}}\right.$, $\left.f_{\text {geo }}, f_{\text {fresnel }}\right\}=\{0.25,0.19,0.05,0.75\}$. Additional quantities are required to specify the geometric kernel [8], representing the ratios of the tree to crown height and of the crown vertical to horizontal extent. These parameters were chosen as the MODIS default of $h / b=2$ and $b / r=1$, respectively, indicating spherical crowns of half the height of the tree. The resulting surface reflectance, unknown in real measurements and which we ultimately

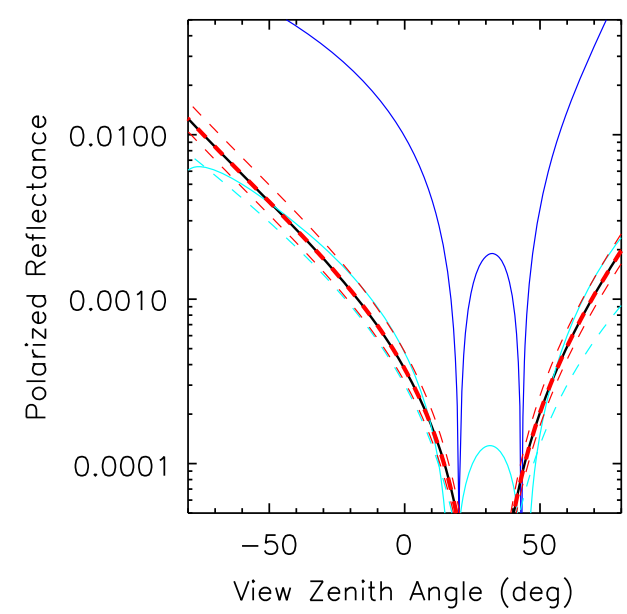

Fig. 1. Gauss-Newton's iterative search for the parameters optimally estimating the synthetic scene described in the text. The plot on the left is relative to the total reflectance, modeled as in Eq. (2); the plot on the right to the polarized reflectance (see Eq. (5)). From knowledge of the reflectance measured by the RSP (blue curve), the method converges fast from the initial guess (path radiance-corrected signal, solid cyan curve fitted by the cyan dashed curve) to the unknown surface signal (thick solid black curve). Fits during different iterations are represented with dashed red curves, with the converged answer of increased thickness. Both for total and polarized reflectance, the residuals get very small after the second iteration already, making it difficult to distinguish intermediate fits from the values found in the final iteration. (For interpretation of the references to color in this figure legend, the reader is referred to the web version of this article.) 
want to retrieve, is shown with a black curve in Fig. 1 for the total (left panel) and polarized reflectance (right panel). The signal simulated for an instrument like the RSP, flying at an altitude of $8.5 \mathrm{~km}$ along the principal plane, is shown by the blue curves.

An initial guess for the model parameters is needed to initialize the iteration. A first estimate for the surface (total and polarized) reflectance is obtained by taking the difference between the observed signal and the (total and polarized) path radiance, defined as the radiance scattered into the instrument's field of view without having interacted with the surface. A common expedient used in radiative transfer to estimate the path radiance is to repeat the simulation that generated a scene with a surface of zero albedo imposed as a lower boundary condition. The total signal corrected for the path radiance is shown with solid cyan lines. This approximation to the surface signal does not take into account possible effects due to multiple interactions between the surface and the atmosphere. In this respect, it is worthwhile noting the vanishing surface contribution to the polarized reflectance for directions close to backscatter where Rayleigh processes take over. The cusp found for the total reflectance is instead the clear hotspot signature typical of vegetation models. Nonetheless, a first fit with Eqs. (9) and (5), shown by the dashed cyan curves, provides parameter values close to the real solution enough to ensure convergence. This first fit is obtained with a Levenberg-Marquardt type of routine, based on the MINPACK FORTRAN package (http://www.netlib.org/minpack/ and translated for the Interactive Data Language (IDL) by Markwardt [45].

When the model is run again with this choice of modeling parameters, the surface signal is found to resemble the first fit (see the almost overlapping red dashed line). The Jacobians output by the code are then used in Eq. (15), implemented with the IDL LA_LEAST_SQUARES procedure, to find the steps $\delta \mathbf{f}$ that are then used to update the parameters. A second iteration produces a significantly different signal that already fits the sought surface reflectance very well. Further iterations account for finer refinements, barely distinguishable in the plots, until the algorithm stops based on a condition imposed on the difference in residuals from the previous iteration (not greater than $10^{-7}$ in this specific case, both for total and polarized reflectance). Based on the discussion above, this fast convergence is an indicator of the low curvature of the hypersurface represented by the cost function (10) in "residual" space. Given the different order of magnitude of the total and polarized reflectance, it is easy to reinforce

Table 1

Parameter evolution during optimization of the synthetic scene.

\begin{tabular}{lllll}
\hline Step & $f_{\text {iso }}(0.25)$ & $f_{\text {vol }}(0.19)$ & $f_{\text {geo }}(0.05)$ & $f_{\text {fres }}(0.75)$ \\
\hline GUESS & 0.165154 & 0.050942 & 0.023309 & 0.625167 \\
ITER 1 & 0.248204 & 0.193857 & 0.048905 & 0.950605 \\
ITER 2 & 0.249348 & 0.187381 & 0.050515 & 0.765108 \\
ITER 3 & 0.249909 & 0.190033 & 0.050013 & 0.738954 \\
ITER 4 & 0.250042 & 0.190115 & 0.049978 & 0.750050 \\
ITER 5 & 0.250001 & 0.189992 & 0.050001 & 0.750467 \\
\hline
\end{tabular}

the convergence criteria by thresholding also the absolute values of the residuals.

Table 1 summarizes the evolution of parameters during the retrieval.

\section{Instrumentation and research flight}

The reflectance terminology involved in remote sensing can be sometimes confusing and we have collected a compendium of relevant quantities in Appendix A. Details on the Research Scanning Polarimeter (RSP) are given in Appendix B. Here, it suffices to specify that this multispectral instrument collects multi-angle measurements of overflown targets in nine selected bands spanning the 410-2264 nm wavelength range. For each angle and wavelength, the quantities being measured are the first three components of the Stokes vector (I, Q and U), which are related to reflectance (more precisely to the Bidirectional Reflectance Factor, BRF) as follows:

$\mathrm{R}_{\mathrm{I}}=\frac{\pi r_{0}^{2}}{F_{0} \cos \theta_{s}} \mathrm{I}$

$\mathrm{R}_{\mathrm{Q}}=\frac{\pi r_{0}^{2}}{F_{0} \cos \theta_{s}} \mathrm{Q}$

$\mathrm{R}_{\mathrm{U}}=\frac{\pi r_{0}^{2}}{F_{0} \cos \theta_{s}} \mathrm{U}$

where $F_{0}$ is the exoatmospheric average solar incident flux, $r_{0}$ the Sun-Earth distance, and $\theta_{s}$ the solar zenith angle.

During the 2010 Carbonaceous Aerosol Radiative Effect Study (CARES) campaign [46] in Sacramento, CA, favorable conditions with snow persisting late in the season provided the opportunity to include a few flight legs over the Sierra Nevada mountain range in one of the research flight of the NASA King Air B-200 on which the RSP was deployed. The flight took place on 10 June, and resulted in a limited dataset useful to analyze and characterize the signal from snowy surfaces (see Fig. 2). Of particular interest is the question of whether the polarized reflectance of snow is spectrally flat as that of other land surfaces, because this property would allow to apply the same algorithms employed for aerosol retrievals [47], in particular optimal estimations based on inverse methods.

The successful collection of the dataset depended both on careful planning and adjustments during flight operations. The snow cover had been continuously monitored via the data downloaded from the NOAA National Operational Hydrologic Remote Sensing Center (http://www.nohrsc.nws.gov/interactive/html/map.html). Although it was not possible to collect snow samples, a few days prior the flight areas with similar snow conditions in the South Tahoe region (Ralston Peak, Eldorado National Forest, CA) were surveilled on foot and the snow was found granular and with considerable water content, as shown in Fig. 2.

The flight legs were designed pondering the best tradeoff among sufficient snow cover, flatness of terrain and orientation of the principal plane: flying in this direction maximizes the range of scattering angles 


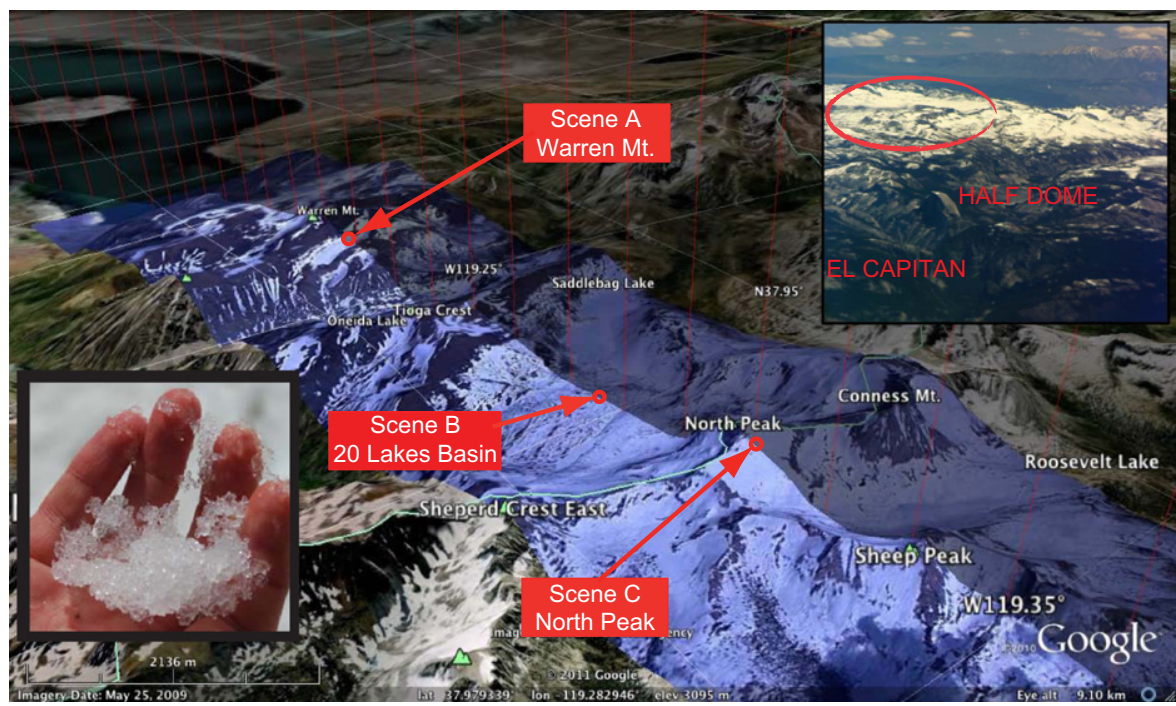

Fig. 2. Flight trajectory (shaded vertical curtain) leading to the collection of the polarimetric dataset over snow. North is at bottom left. Coming from Mono Lake (upper left), we overflew the high country past Mt. Warren onward to North Peak on the Sierra Divide (light green), which at this location also marks the border between Inyo National Forest and Yosemite National Park. The real-time panorama swath was created by blanketing the 3D terrain in Google Earth with a merge of images captured by the B-200 downward looking camera. The inset shows the appearance of snow on Ralston Peak (Eldorado National Forest, CA) on 6 June, with wet clusters of nearly spherical grains a few millimeters in diameter. Although the sampling location was only relatively close in space and time, these late-season snow conditions were likely to be similar to those scanned during the research flight. (For interpretation of the references to color in this figure legend, the reader is referred to the web version of this article.)

spanned during RSP scans. Also, wind forecast were monitored since head or tail winds limit aircraft yaw, which prevents features limited in size from being scanned at all available angles. Experience acquired during the analysis of RSP data from previous campaigns confirms that corrections for "crabbing" are indeed a major challenge during data aggregation.

Airborne determination of the reflection properties of a surface benefits from low-altitude passes, so as to maximize resolution and minimize atmospheric interference. Nevertheless, stable aircraft course is challenged by the turbulence associated with a rugged topography. With time constraints preventing the possibility of repeated overpasses, we chose to fly at an altitude that preserved the High Spectral Resolution Lidar (HSRL [48]) operations, since this instrument provides vertical characterization of the atmosphere below the aircraft but cannot be operated below altitudes established by Federal Aviation Administration regulations on eye-safety.

The most interesting data were collected along a flight segment from Mono Lake to Yosemite National Park (see Fig. 2 and Appendix C). Curiously, this area belongs to regions surveyed in the limited set of published works that were found to deal with hyperspectral imaging of alpine snow in the United States [49]. Regional variability and interconnection between grain size and wetness were investigated based on Airborne Visible InfraRed Imaging Spectrometer (AVIRIS) data collected near Tioga Pass [49], and the effect on spectral reflectance of red algae (Chlamydomonas nivalis) blooming onto old snowfields was observed by the same instrument on the drainages of Mt. Conness [50,51].

At the time the transect took place, the air was exceptionally clean of aerosols with an aerosol optical depth below the aircraft measured by the HSRL equal to 0.015 (at $532 \mathrm{~nm}$ ). Last-minute, in-flight adjustments worth mentioning included:

1. descending at lower altitude, in this case the minimum allowed for HSRL operations $(\sim 7.5 \mathrm{~km})$. Flying over plateaus with an average elevation of $3200 \mathrm{~m}$, the RSP resolution was $\sim 60 \mathrm{~m}$. From the same altitude, scanning a target throughout the whole RSP field of view $\left( \pm 60^{\circ}\right)$ required a straight leg of a length $x=2 \mathrm{~h} \tan 60 \sim 7 \mathrm{~km}$ ( $5.3 \mathrm{~km}$ for the reasonable range of $\pm 40^{\circ}$ );

2. disengaging the autopilot, which tends to overshoot the corrections to variations in attitude. This choice was particularly fortunate as manual flight greatly stabilized the orientation of the scanning plane throughout subsequent scans;

3. reducing the speed, which also improves resolution. This maneuver was beneficial only due to the flight leg being aligned with the wind direction;

4. deviating approximately $20^{\circ}$ from the planned course, to overfly the flattest terrain. Varying the course according to visually identified features is difficult since the visibility from the cockpit is limited in the downward direction. Also, the variation must be estimated several kilometers in advance to make sure the feature of interest is overflown within a straight leg.

\section{Optical properties of snow}

Snow can be physically considered as a lattice of ice grains, whose radii are typically between $50 \mu \mathrm{m}$ and $1000 \mu \mathrm{m}$ depending on age, although significant amount of liquid water can be present especially after the onset of 
melting. The complex indices of refraction of water and ice, together with the size and shape distribution of the ice grains, therefore determine the optical properties of this highly scattering medium. The overall picture is complicated by the assortment of grain types [52,53] and a remarkable tendency to metamorphism, at the point that characterizing or even defining size and shape is often a struggle for both measurements and models. Moreover, topographic effects and atmospheric agents can easily alter the essentially isotropic properties of fresh snow resting on a flat ground. Snowfields deposited on rugged terrain, typically associated with alpine environments, receive special attention by the remote sensing community motivated by the need of inferring important information on the hydrological cycle $[54,49]$. Such scenario can be challenging to model, because radiative transfer codes typically rely on the assumption of a bottom boundary described by a surface located at a well defined altitude and of unlimited horizontal extent. Further caveats are represented by sub-pixels heterogeneity $[49,55]$ and shadowing effects due exposed soil and vegetation.

For wavelengths in the visible region of the electromagnetic spectrum, snow is the natural surface of highest reflectance, with a spectral albedo that can reach values up to 0.98 for fresh dry snow [56]. The white appearance is due to nearly constant behavior of the real part of the refractive index, which is also very similar for both the ice and water phase with that of the ice being only slightly shifted towards longer wavelengths. The absorption coefficient (imaginary part of the refractive index) is also similar, and more importantly is very small preventing liquid water from appreciably affecting the reflectance.

As the spectral window shifts towards the near-infrared and up to $2.5 \mu \mathrm{m}$, the properties drastically change and the "color" of snow becomes all but monotone. The absorption coefficients of both ice and water experience a similar, remarkable increase covering seven orders of magnitude. As a consequence, the reflectance plummets, to partially recover only around 1.9 and $2.4 \mu \mathrm{m}$. Very dark intervals are found at $1.5 \mu \mathrm{m}$ and $2.0 \mu \mathrm{m}$. Differently than in the visible, the presence of liquid water can affect the reflectance, also outside the $1.35-1.75 \mu \mathrm{m}$ region where ice is slightly more absorptive. The reason is that liquid water promotes clustering, leading to larger ice grains (up to a fraction of a centimeter) of complex shape.

Snow albedo increases with the solar zenith angle. This effect is detectable in the visible, and very evident in the near-infrared, where the strongly forward-scattering ice grains (especially those of larger size) have less of a chance to attenuate via absorption a beam incident at a grazing geometry than they have to attenuate a more penetrating normal beam. The higher probability of absorption determined by longer in-grain paths also explains the sensitivity to grain size, which is greatest at $1.0-1.3 \mu \mathrm{m}$ and has been successfully modeled and applied to observational datasets [57-59]. All algorithms exploit the ratios between relatively unaffected bands in the visible and largely affected bands in the Near InfraRed (NIR).
In terms of angular behavior, the most prominent observed feature is the increase in reflectance at forward scattering angles. There is some indication that this increase is partially suppressed by both surface roughness and wetness, but accurate quantification and accepted explanation for these effects is still lacking [60]. Different water phases can be detected exploiting the signal collected in water absorption bands by hyperspectral instruments [61]. This task is of particular interest, because of the importance of monitoring snow melting processes. A weaker increase in reflectance is measurable also in the backscatter region, and can be enhanced by roughness. Specular signatures are missing from most of snow samples analyzed in the published literature [60]. In some cases, wet samples show weak structures [62], but peaks in the specular direction were only detected in rough ice layers, for which the mirror effect of macro-facets is the most logical explanation.

These arguments obviously hold for a pure (at most contaminated by water) and well formed (semi-infinite) snowpack. Snow depth and impurities deposited over or embedded within the snow layer have a large effect on the reflectance: the former because of partial exposure of the underlying surface, the latter depending on the radically different refractive index of black particulate such as soot. The thickness required to make a snow layer optically thick depends on the grain size and the wavelength. A layer of a few millimeters is sufficient to mask the underlying surface at long wavelengths, while a few centimeters of fresh snow to tens of centimeters of wet snow are required to fulfill the same approximation in the visible. The effect of impurities can at times be drastic. While the high absorption properties of ice in the NIR are little affected by the presence of extraneous absorbers, in the visible even a few parts per billion by weight of dark particles are sufficient to contaminate the transparency and lower the albedo. This phenomenon has received much attention due to its involvement within a feedback mechanism leading to increased melt rate which can affect climate on a global scale $[63,64]$.

Radiative transfer simulations exploring the sensitivity to different parameters were prompted by the seminal studies of Warren and Wiscombe [65,66], and continued in the following decades [67-73,57]. Very few studies extended the modeling to the full Stokes vector [74,75], also because the scarcity of observational datasets [76-78]. Most of the knowledge cumulated so far comes from in situ measurements that exploit goniometers in the field or in the laboratory $[78,79]$. The degree of linear polarization was in any case measurable with satisfactory signal to noise ratio only in the forward scattering region, and shows to be weak in the visible, getting stronger in the infrared. This fact is explained by the fewer scattering events undergone by long wavelengths before they are reflected off the surface; at visible wavelengths larger penetration depths allow multiple scattering to suppress polarization. Specular reflection peaks are associated to strong polarization, but as previously mentioned they have only been detected in frozen, macroscopically rough layers (and only partially in wet samples). More investigations are needed to establish the weight of this claim, 
especially regarding the degree of polarization measured around the Brewster's geometry (roughly $52^{\circ}$ of incidence for ice), for which polarization by reflection is expected to be maximized. On the other hand, a most interesting feature that seems confirmed is the significant reduction of the forward polarization by wet snow (as opposed to dry old snow), which could prove diagnostic for the detection of water content.

\section{Data analysis and discussion}

The negligible aerosol optical depth measured by the HSRL (see Section 3) greatly simplified our analysis since the atmospheric correction consists only of the removal of the Rayleigh contribution. In any case, accurate analyses of RSP data rely on correction for band-specific gaseous absorption. The radiance measured in the Short-Wave InfraRed (SWIR) channels at 1594 and $2264 \mathrm{~nm}$ need be corrected for water vapor absorption. The ratio between the signal in a channel subject to water vapor absorption and one in a window can be used over bright areas to retrieve the precipitable amount $[80,81]$. The RSP offers this possibility through the reflectances measured at $960 \mathrm{~nm}$ and $864 \mathrm{~nm}$ which were used to calculate

$\frac{\mathrm{R}_{\mathrm{I}}(960)}{\mathrm{R}_{\mathrm{I}}(864)}=\exp ^{-\alpha(\mathrm{AM} \mathrm{W})^{\beta}}$

where AM is the airmass, $\mathrm{W}$ is the water vapor column (in precipitable $\mathrm{cm}$ ), and $\alpha$ and $\beta$ are instrument-specific constants [82].

The possibility of utilizing to this purpose the bright scans over snow was enticing. Nevertheless, an ice/water mix typical of late-season snow can spoil the usefulness of the ratio, because the imaginary part of the refractive index of ice is appreciably less than that of water at $960 \mathrm{~nm}\left(3.5 \times 10^{-6}\right.$ versus $\left.7.5 \times 10^{-6}[83,84]\right)$. The amount of precipitable water retrieved with the procedure was $1.16 \mathrm{~cm}$, indeed an implausible value for the $4 \mathrm{~km}$ of atmosphere between the aircraft and the ground. Repeating the procedure for scans over the Tioga Crest (mostly exposed, talus/scree slopes of metamorphic rocks at $3600 \mathrm{~m}$ asl, see Appendix C) and over sunglint reflected off Mono Lake $(1950 \mathrm{~m}$ asl), the retrieved value was $0.15 \mathrm{~cm}$. This low value allowed to skip the correction for water vapor for the two RSP bands.

Minimal corrections for $\mathrm{NO}_{2}$ and $\mathrm{O}_{3}$, amounting to less than $0.5 \%$, were applied the $410 \mathrm{~nm}$ and $469 \mathrm{~nm}$ channels, based on the concentration of these gases retrieved form the Ozone Monitoring Instrument (OMI [85]) and TOMS.

It is recommended $[86,9]$ that if the inversion produces a negative weight for one of the total reflectance kernels, the inversion be repeated with that value constrained to zero. This sequence ensures that the quasi-orthogonality of the kernels is fully exploited, minimizing the risk of unstable inversion and/or retrieval of unphysical reflectances. Since the analytical form of the Jacobians output by the DA code corresponds to $d R(f) / d \log f_{k}$, the solution to Eq. (15) actually provides $\delta \log f$. To constrain the search to positive values of the kernels' weights, this step size can be used to update the parameters within a logarithmic-exponential transformation

$$
\begin{array}{r}
\exp \left[\log \mathbf{f}^{k}+\delta \log \mathbf{f}^{k}\right]=\exp \left[\log \mathbf{f}^{k}+\delta \mathbf{f}^{k} / \mathbf{f}^{k}\right] \\
=\mathbf{f}^{k} \exp \left[\delta \mathbf{f}^{k} / \mathbf{f}^{k}\right] \sim \mathbf{f}^{k}\left[1+\delta \mathbf{f}^{k} / \mathbf{f}^{k}\right]=\mathbf{f}^{k}+\delta \mathbf{f}^{k}
\end{array}
$$

A discussion on the applicability of this kind of transformation to parameter estimation is given in Dubovik and King [87].

Some authors [A. Lyapustin, personal communication] prefer instead to regard the kernels as purely mathematical functions and accept negative weights; the ideal treatment is still a source of debate. The geometric and volumetric kernels were not designed for a peculiar surface as is the case for snow, whose reflectance is largely dominated by the isotropic component. Small deviations, occasionally observed at very large angles and mostly affected by scanning uncertainties on a rough terrain, can introduce large variability in the weights, including small negative values indeed observed for some of the channels in our analysis. A complete characterization of snow total reflectance model is hampered by the unique nature of this limited dataset. Since the primary goal of this study is to quantify the spectral variability of the polarized reflectance, negative occurrences were accepted as were, and a thorough study of the performance of surface reflectance models on snow was delayed to a more representative dataset.

Once the iterative procedure has converged, the diffuse component calculated by the model can be subtracted from the observations, and the difference divided by the two-pass transmittance to obtain a best estimate for the surface reflectance. This result overlaps to the converged answer if the model is capable of an accurate description of the reflection of the diffuse component throughout the range of viewing angles. As observed for other land surfaces $[47,88,89]$, the Fresnel model performed worst close to the backscatter direction, where both the atmosphere and the surface introduce very small polarization often characterized by inversions. In this angular region, due to the virtually identical reflectivity predicted at backscatter (perpendicular incidence) for the parallel and perpendicular components, the theoretical polarized reflectance instead decreases monotonously to zero.

In the following we contrast the spectral behavior of the snow surface polarized reflectance obtained after convergence of the iterative scheme at each wavelength with that of a standard atmospheric correction.

The standard scheme is based on subtraction of direct and diffuse atmospheric contributions, including an estimate of the multiple interactions coupling the surface and the atmosphere. For the polarized reflectance, we tested an ad hoc approach used in past surface polarized reflectance retrievals from POLDER and RSP measurements $[13,90]$. Neglecting multiple interactions, the polarized reflectance $\mathbf{R}_{P}(\lambda, z)$ measured by a polarimeter at an altitude $z$ can be written as

$\mathbf{R}_{P}(\lambda, z)=\mathbf{R}_{P}^{a t m}(\lambda, z)+\mathbf{T}^{\uparrow \downarrow}(\lambda, z) \mathbf{R}_{P}^{s r f}(\lambda)$

where $\mathbf{R}_{P}^{a t m}(\lambda)$ and $\mathbf{R}_{P}^{\text {srf }}(\lambda)$ are the path and surface polarized reflectance, respectively (see Section 2). The latter is weighted by the two-pass transmittance from the top of 
the atmosphere to the surface and up to instrument altitude for each viewing angle, $\mathbf{T}^{\uparrow \downarrow}(\lambda, z)$. Note that we have maintained the vectorial notation to remember that we are dealing with arrays of measurements at different viewing geometries (scattering angles), and reintroduced the explicit dependence on wavelength. In absence of appreciable aerosols, the transmittance is determined by the molecular optical depth $\tau^{m}$ and the coupling effects can be approximated by rescaling $\tau^{m}$ with a factor $\psi$. From Eq. (21), $\psi$ is obtained through a linear regression on

$\mathbf{R}_{P}(\lambda, z)-\mathbf{R}_{P}^{a t m}(\lambda, z)=\mathbf{R}_{P}^{\text {srf }}(\lambda) \exp \left[-\psi\left(\frac{\tau_{0}^{m}(\lambda)}{\mu_{0}}+\frac{\tau_{z}^{m}(\lambda)}{\boldsymbol{\mu}_{\boldsymbol{v}}}\right)\right]$

viz.,

$\psi=\frac{1}{\log \mathbf{T}^{\uparrow \downarrow}(\lambda, z)} \log \left[\frac{\mathbf{R}_{P}(\lambda, z)-\mathbf{R}_{P}^{a t m}(\lambda, z)}{\mathbf{R}_{P}^{\text {sff }}(\lambda)}\right]$.

Attempts to reproduce the factors reported in the literature $[13,90]$ found that the latter were consistently overestimated. A possible reason for this lack of reproducibility is that those studies retrieved the factor $\psi$ in presence of significant aerosol loads, which dominate the polarization signatures therefore impacting the accuracy with which the corrective term relative to the Rayleigh contribution is determined.

The retrieved total surface reflectance decisively points to the typical signatures of snow, with high intensity measured in all three scenes by the visible channels and the expected drastic decrease in the SWIR. More importantly, the variations in visible "albedo" are remarkable among the three scenes. It has to be noted that what plotted in Fig. 4 are rigorously speaking apparent reflectances. In particular, the western face of North Peak (Scene C) is characterized by a constant slope of about $40^{\circ}$. Given the close alignment of the direction of steepest slope to both flight trajectory and principal plane, a simple correction to the illumination geometry can be introduced by adjusting the solar zenith angle in Eq. (B.1). This correction for Scene C can amount to a $80 \%$ reduction of the reflectances and bring it closer to Scenes A and B. Scene B presents a slightly upward slope as well, which once corrected for would increase the reflectance. It is nevertheless unlikely that the apparent character of these reflectances is the sole responsible factor for the observed variability, especially considering the differences assessable by the naked eye among to the three snowfields.

It is noteworthy that Scene B (Fig. 3) exhibits the highest reflectance at $670 \mathrm{~nm}$, making the visible color of this snowfield slightly pink. This behavior can possibly be attributed to the presence of the snow algae common in this area, as discussed at the end of Section 3.

Finally, the presence of water/ice mix agrees with the enhanced backscatter measured over the analyzed snowfields, although a major contribution to this feature can be also ascribed to surface roughness as observed by Peltoniemi et al. [60].
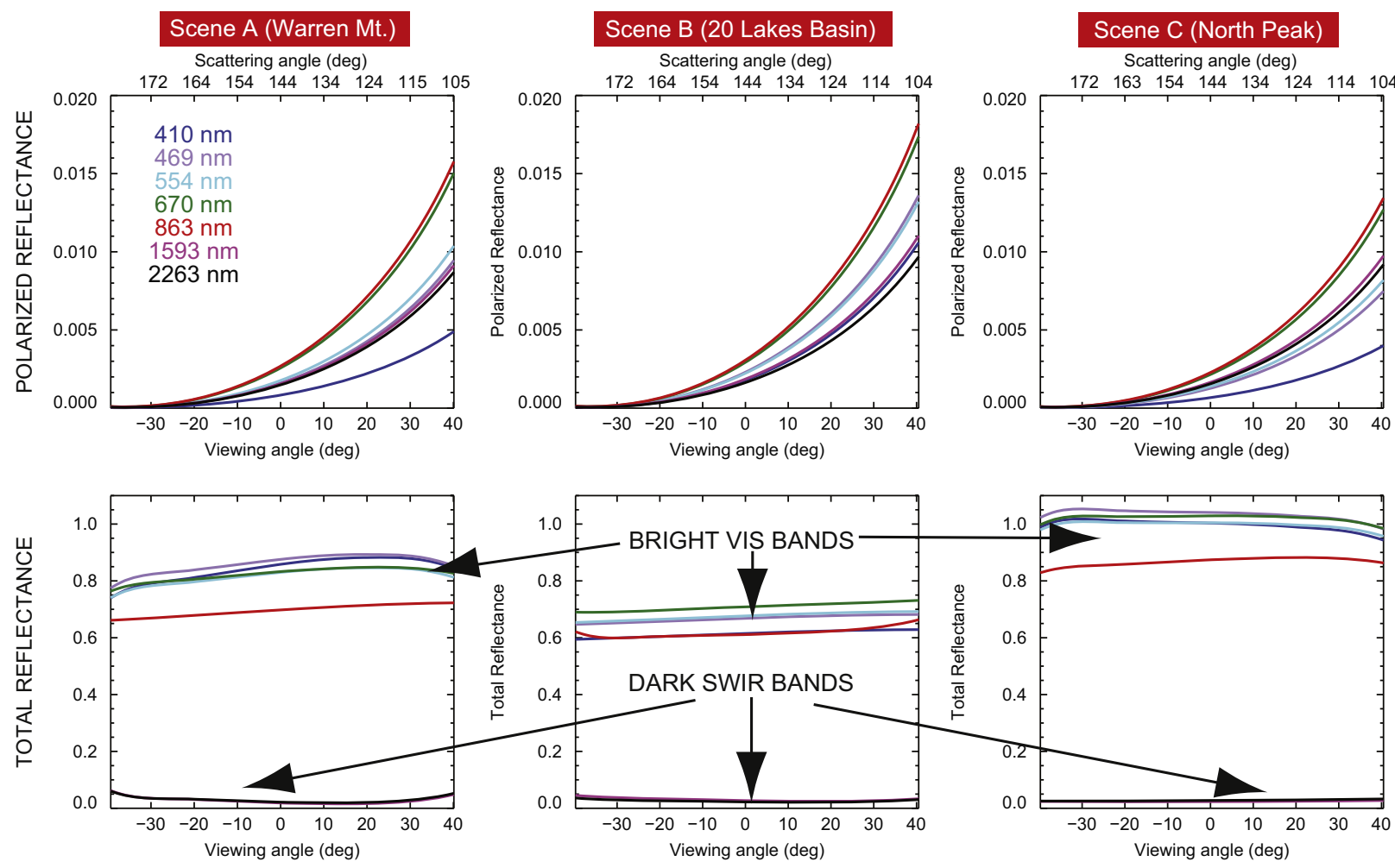

Fig. 3. Surface reflectance retrieved with the iterative procedure described in Section 2 . The three columns are relative to the three selected scenes (cf. Fig. 2). The top row pertains to the polarized reflectance, and the bottom row to the polarized reflectance. Note the large variations in total reflectance among the three scenes. The spectral variability and the absolute value of the polarized reflectance are instead small. 

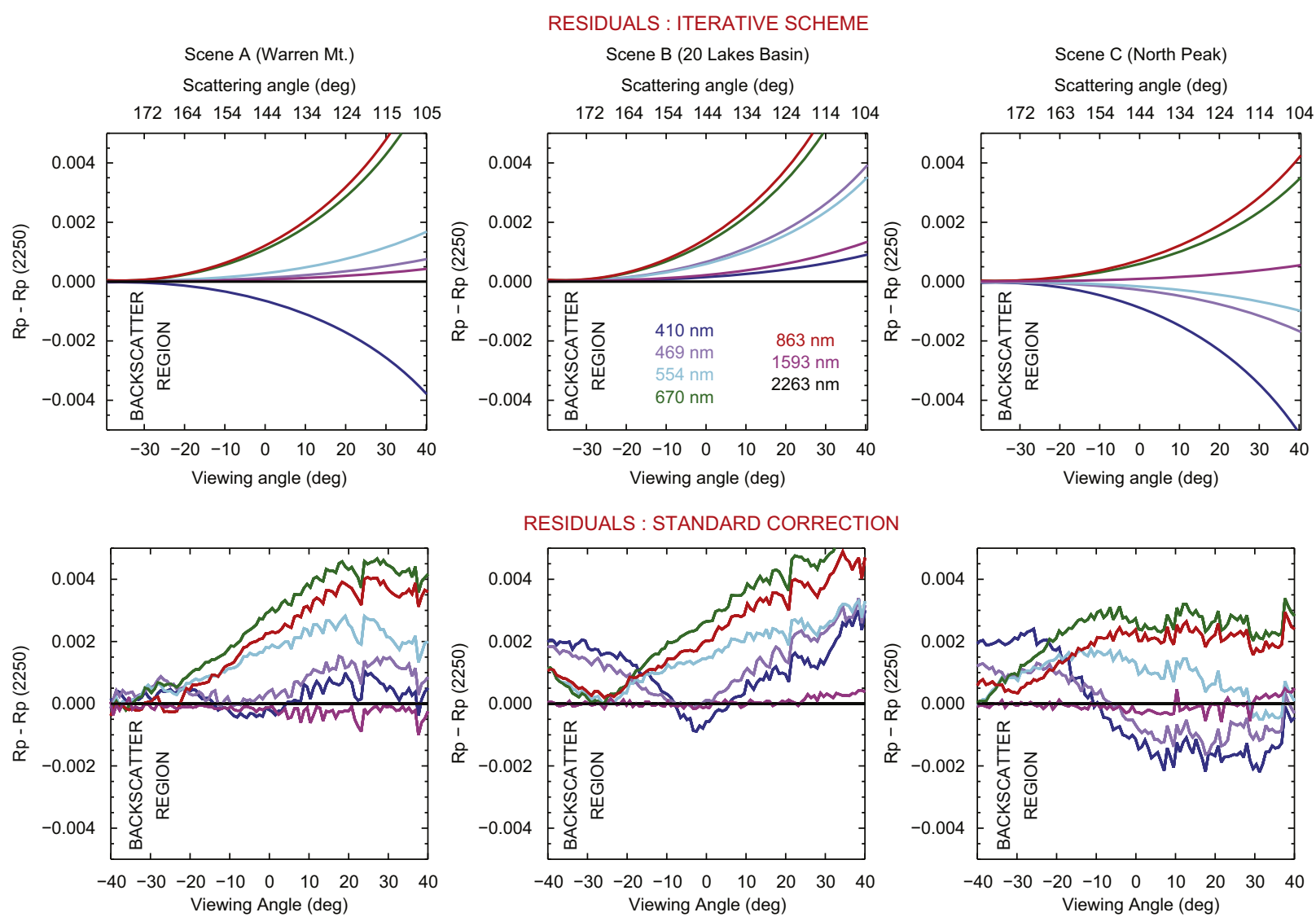

Fig. 4. The residuals in the top row of this figure correspond to the differences between the surface polarized reflectances retrieved for each RSP wavelength (upper row of Fig. 3) relative to the $2264 \mathrm{~nm}$ channel. Away from the backscattering region, where land models are known to fail, similar results are obtained via a standard correction based on the simplistic subtraction of atmospheric scattering contributions (bottom row).

For the polarized reflectance, the two methods give very similar results, with residuals limited to $2 \times 10^{-3}$ except for the $670 \mathrm{~nm}$ and $864 \mathrm{~nm}$ in Scenes A and B. This value is $5-10$ times higher than that found for other land surfaces. It can also be seen that the model (upper row) does not adequately describe the behavior in the backscatter region, i.e. at scattering angles $>160^{\circ}$.

Recognizing the similarity between the angular behavior of the polarized reflectance retrieved over the surveyed snow and that of rough ice clouds, we extended our study attempting to retrieve surface descriptive parameters. The approach is analogous to that described in a recent publication where RSP measurements were exploited for the retrieval of optically relevant parameters of ice crystals forming cirrus clouds [81]. Firstly, a database of optical properties of single plates and columns was constructed based on geometric optics [91] with size, aspect ratios and small-scale roughness as free parameters [92-94]. Then radiative transfer simulations were run for a layer of ice particles of high optical depth (200) occupying the first meter of the model atmosphere. The departure from the data of the polarized reflectance simulated for each habit in the database (Root Mean Square Error, RMSE) was stored, and used as a measure of the goodness of the fit. A sample result of this procedure is presented in Fig. 5 for Scene B. Here we chose to exploit the polarized reflectance at $864 \mathrm{~nm}$ to minimize uncertainties associated with absorption estimates, since ice does not appreciably absorb at this wavelength. The upper panel of Fig. 5 shows that good fits are obtained for a variety of ice models. The lower panel shows a contour plot of the RMSE. Looking for minima (marked with red diamonds), it is observed that all optimal fits pertain to crystals affected by a surface roughness of $0.3-0.35$. The aspect ratios are instead not unambiguously retrieved and include a collection of extreme geometries (i.e., very long columns), a fact that can potentially be exploited when attempting the construction of a surface model. Large departures occur from the model curves relative to pristine or nearly-pristine ice crystals, since these habits generate well-known halos not present in the analyzed data.

A final argument is especially important to put this work in perspective, and it is summarized in Fig. 6. Here we show with solid lines the spectral behavior of the polarized reflectance acquired by the RSP just $20 \mathrm{~min}$ after the B200 surveyed the snowfields. At this time, the aircraft was overflying the Fresno area where the HSRL measured an aerosol optical depth close to 0.1 at $532 \mathrm{~nm}$. The dashed lines result from multiplying the surface signals retrieved for the snow (Scene B) by the transmittance factor $\exp \left[-\tau_{\lambda} /\left(\mu_{0}+\mu\right)\right]$, and therefore approximate 

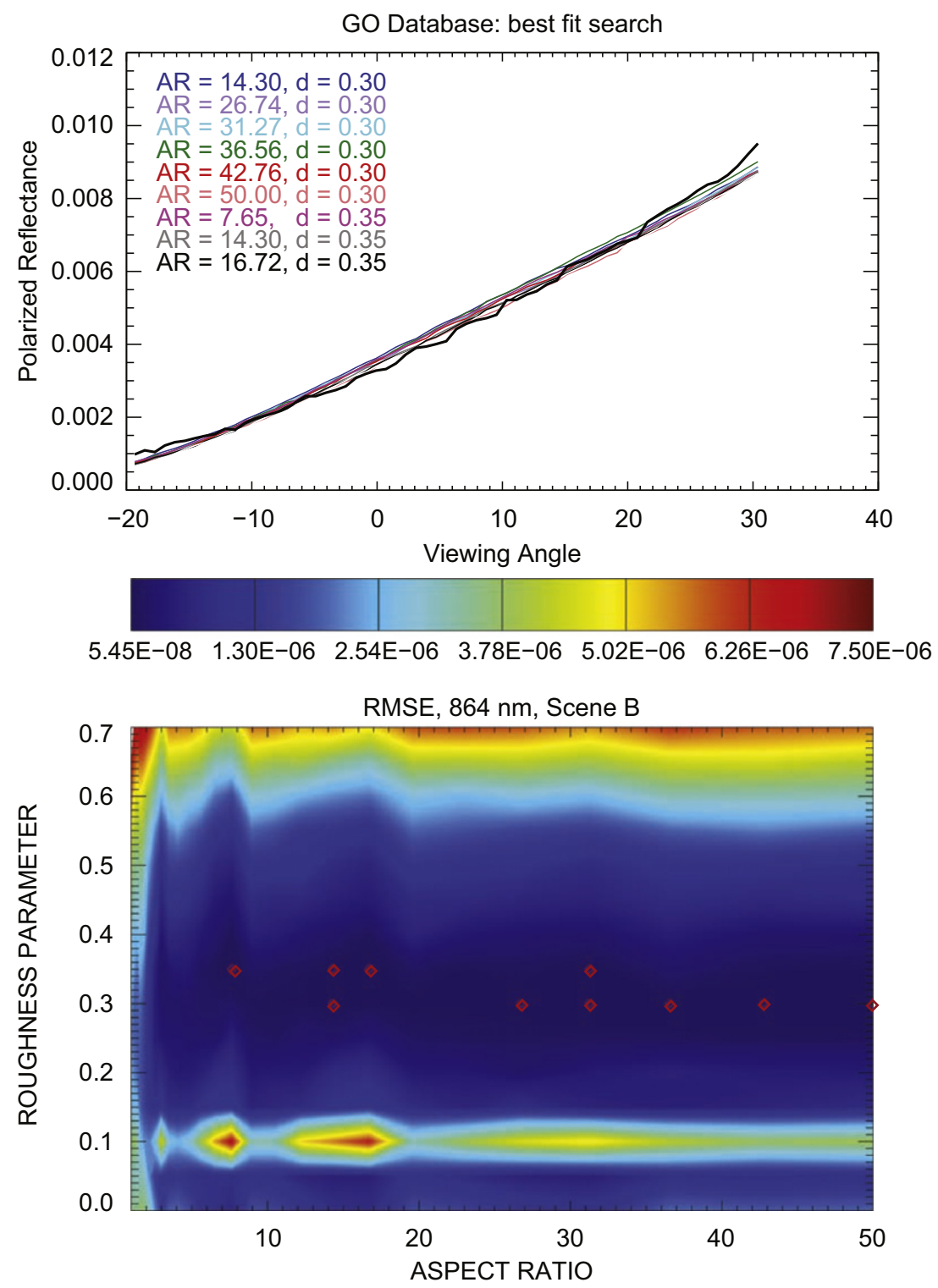

Fig. 5. Search for a best fit to the polarized reflectance measured over Scene B. The snow layer was treated in radiative transfer simulations as a thick ice cloud at the surface, and the ice crystals descriptive parameters let vary according to a database calculated via geometric optics. The lower panel shows a contour plot of the RMSE (departure from the model) as a function of model parameters. All best fits (red diamonds) correspond to grains characterized by a roughness of $\sim 0.3$ and not well-determined, extreme aspect ratios. (For interpretation of the references to color in this figure legend, the reader is referred to the web version of this article.)

the surface contribution as observed from the RSP altitude if the ground around Fresno had been covered in snow. The spectral AOD was determined for a simple aerosol model $\left(r_{\text {eff }}=0.15 \mu \mathrm{m}, v_{\text {eff }}=0.15\right)$, with a particle number concentration adjusted so as to yield the HSRL-measured optical depth. It should be noted that as long as the single scattering approximation holds, the polarized reflectance is proportional to the optical depth itself (see, for example, Eq. (2.1) in [16]). For this moderate aerosol load already, and more so at increasing optical depths, the surface contribution to the measured polarized reflectance is small over a large portion of the angular range. With the exception of the $670 \mathrm{~nm}$ and $864 \mathrm{~nm}$ bands, at which the analyzed snowfield exhibited somewhat peculiar behavior, the spectral variability is also limited. This fact suggests that, pending a more thorough characterization based on data collected over flatter snow surfaces, polarization measurements can be exploited to improve the estimate of the surface contribution, thereby increasing the accuracy of aerosol retrievals.

\section{Conclusions}

Airborne polarimetric data over snow, with the accuracy provided by an instrument such as the RSP, are to our knowledge unprecedented. This paper reports the first 


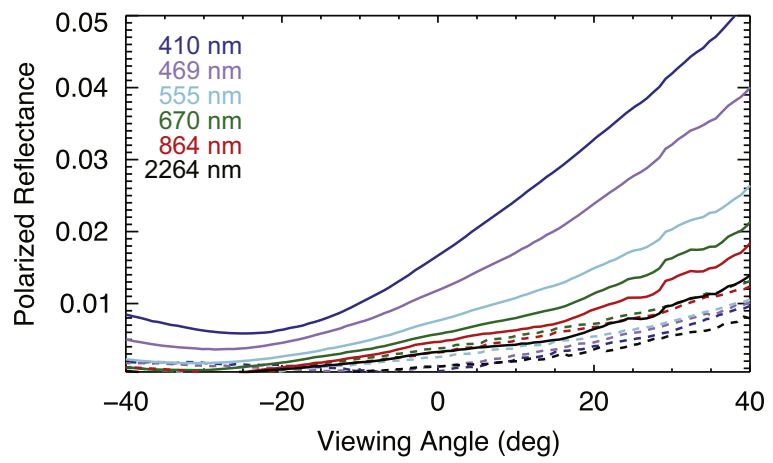

Fig. 6. Comparison between the small magnitude of the snow polarized reflectance (dashed lines) and the polarized reflectance measured 20 min later in the flight (solid lines) over the Fresno area, characterized by an $\mathrm{AOD}_{532}=0.1$. The RSP $1590 \mathrm{~nm}$ band is excluded for clarity.

known investigation of the behavior of the polarized reflectance of snow over the 410-2264 nm spectral range, of interest to both the cryosphere and aerosol remote sensing communities. The dataset was collected during an RSP survey over alpine snowfields in the Sierra Nevada range, in June 2010. The surface signal retrieved via a standard atmospheric correction is compared with the results obtained from an iterative correction scheme, which automatically isolates the surface contribution from remote sensing polarimetric observations. Based on the linearization of a Doubling-Adding radiative transfer code with respect to the surface descriptive parameters, this method eliminates the need of an atmospheric correction.

The primary conclusion of this study is that the polarized reflectance of the analyzed snow type is not as spectrally neutral ("gray") as that of other land surfaces, but the differences are nonetheless small. The absolute value of polarized reflectance is also small. These two facts together augment the confidence in the usefulness of polarimetric measurements to effectively separate surface and atmospheric contribution in the analysis of remote sensing measurements. The application of the iterative correction scheme highlights how current surface models do not fully reproduce the polarization signatures of snow, especially near backscatter where the models are known to fail even for the traditional land surfaces for which they were designed.

We have also attempted to model the snow layer in radiative transfer computations as an ensemble of ice crystals at the surface. The results show that the polarization signatures of the analyzed snow fields resemble those of an optically thick, rough ice cloud.

The acquisition of the dataset was a particularly valuable experience because of the challenges presented when scanning spatially limited targets on uneven terrain, as opposed to horizontally homogenous aerosol layers or cloud decks. Successful data collection was possible due to over 10 years of experience in RSP research flights, and is auspicious for the collection of a set of dedicated measurements. At present, the RSP is arguably the best available asset for high-accuracy, airborne characterization of the polarized reflectance of snow and ice landscapes, and consequently for the determination of optical and microphysical descriptive parameters of both the surface and the aerosols above it.

\section{Acknowledgments}

M. Ottaviani was supported by an appointment to the NASA Postdoctoral Program at the NASA Goddard Institute for Space Studies, administered by Oak Ridge Associated Universities through a contract with NASA. The authors also acknowledge the additional support offered by the Glory Mission project and the NASA Radiation Sciences Program managed by Hal Maring. The collection of this unparalleled dataset was the result of an exceptional effort spent by a number of people involved in flight planning and execution during the CARES campaign. We are particularly grateful to Rick Yasky and Mike Wusk: their piloting skills all showed in the maneuvers performed to guarantee best data quality. We appreciate the responsiveness of Crystal Schaaf, Miguel Roman, Alexei Lyapustin and Charles Gatebe during discussions on the performance of the surface reflectance models, and that of Tom Painter and Felix Seidel on issues regarding several aspects specific of Sierra snow. Many thanks to Luc Mehl, Claudio Berti, Alessio Ponza and Andrew Kylander-Clark for having provided interesting information on the geology of the Tuolumne Intrusive Suite. Finally, the knowledge shared by Bastiaan Van Diedenhoven, Josh Ferris and Tomonori Tanikawa was inspirational in driving this study.

\section{Appendix A. Radiometric definitions}

This appendix lists a series of definitions pertinent to reflectance measurements consistent with the nomenclature recommended by Nicodemus et al. [95], albeit tailored to remote-sensing applications as in Schaepman-Strub et al. [96] and Thomas and Stamnes [97].

Electromagnetic radiation transports energy through space at a rate determined by the flux of the associated Poynting vector [29]. At any point in space and time, light can therefore be regarded as radiant energy, $Q$, measured in Joules (J). A spectral counterpart can be defined for energy and all the quantities discussed henceforth, by considering the derivative with respect to wavelength. This dependence is dropped for simplicity from the notation, since it is straightforwardly reintroduced whenever the application requires it.

The energy per unit time is the radiant flux or power, and has the units of Watts

$\Phi=\frac{d Q}{d t}(\mathrm{~W})$.

The Radiant flux density is the radiant flux per unit area

$E=\frac{d \Phi}{d A}\left(\mathrm{~W} \mathrm{~m}^{-2}\right)$

and is also called irradiance, or radiant exitance $M$ when considering radiation originating from a surface. The radiance $L$ embodies the idea of a pencil-beam of radiation and is defined as the infinitesimal amount of radiant flux 
contained within a solid angle $d \omega$ oriented in a specified direction $\left(\theta_{r}, \phi_{r}\right)$, and crossing a surface $d A$ :

$L=\frac{d^{2} \Phi}{\cos \theta d A d \omega}\left(\mathrm{W} \mathrm{m}^{-2} \mathrm{sr}^{-1}\right)$.

Here $\cos \theta$ is the angle between the surface normal and the direction of propagation, so that $d A \cos \theta$ represents the area projected onto a plane normal to the "beam". This definition implies that the radiance is independent on the particular orientation of the surface $d A$. It also implies that the irradiance is obtained by integrating the radiance over all the hemisphere:

$E=\int_{-\pi}^{\pi} \int_{0}^{\pi / 2} L\left(\theta_{r}, \phi_{r}\right) \sin \theta_{r} \cos \theta_{r} d \theta_{r} d \phi_{r}$

which in the specific case of isotropic illumination reduces to $E=\pi L$.

Radiance is sometimes misleadingly referred to as intensity. The (radiant) intensity $I$ is instead correctly defined as the amount of radiant flux contained in the elemental cone:

$I=\frac{d \Phi}{d \omega}\left(\mathrm{W} \mathrm{sr}^{-1}\right)$.

To describe the local reflection properties of a surface, the light scattered by a surface element in the direction $\left(\theta_{r}, \phi_{r}\right)$ must be related to that incident on the same surface element from the direction $\left(\theta_{i}, \phi_{i}\right)$. The radiance traveling in an infinitesimal cone is $d L=L d \omega$. The ratio of the radiance reflected by a surface element to the power (irradiance) which invests it is the Bidirectional Reflection Distribution Function (BRDF):

$\mathrm{BRDF}=\frac{d L_{r}}{L_{i} \cos \theta_{i} d \omega_{i}}=\frac{d L_{r}}{d E_{i}}\left(\mathrm{sr}^{-1}\right)$.

This theoretical definition contains undetectable infinitesimal quantities, and is therefore not applicable to real measurements. Photometers deployed for atmospheric studies measure a radiant flux that has generally undergone scattering events: the true physical quantity being measured is thus the fraction of incident flux (irradiance) reflected in the direction of observation (exitance), or the reflectance. A common way to express a reflectance measurement is through comparison with the response that an ideal Lambertian surface with a spherical albedo equal to 1 would give under the same illumination condition. The ratio between the two is the Bidirectional Reflectance Factor (BRF), which coincides with the reflectance measured by the RSP (see Eqs. (B.1)-(B.3)) since the variations in surface properties across the narrow IFOV (for nominal flight altitudes) can be assumed to be negligible.

Several derived quantities are tailored to specific applications. The Directional-Hemispherical Reflectance (DHR), also known as planetary albedo, is obtained by integrating the BRDF of a plane-parallel beam over all viewing angles. The Bidirectional-Hemispherical Reflectance (BHR) is also called spherical albedo and results from the integration of the BRDF over both illumination and viewing angles. In the MODIS community, these quantities are referred to as "black-sky" or "white-sky" albedo, respectively (the latter under isotropic illumination conditions).

\section{Appendix B. The research scanning polarimeter (RSP)}

The Research Scanning Polarimeter (RSP [14]) was built at SpecTIR, under commission of the NASA Goddard Institute for Space Studies (GISS) science team, to collect data on aerosol and clouds useful for climate studies. It has now over 13 years of history of research flights, and successful operations prompted its selection as a prototype for the Aerosol Polarimetry Sensor, that was unfortunately lost as a consequence of a rocket failure during the launch of the NASA Glory satellite mission on 4 March, 2011.

The RSP optical assembly consists of three pairs of boresighted refractive relay telescopes, each pair collecting measurements in three spectral bands. Of the resulting nine channels, six have centerbands in the visible and near infrared portion of the spectrum $(410,469,555,670$, 864 and $960 \mathrm{~nm}$ ) and exploit blue enhanced silicon photodiodes, whereas three are in the shortwave infrared (1594, 1880 and $2264 \mathrm{~nm}$ ) and exploit HgCdTe detectors cooled to $150 \mathrm{~K}$.

The paired design is required to determine the I, $\mathrm{Q}$ and $\mathrm{U}$ Stokes parameters from the simultaneous measurement of the two orthogonal polarization states at $0^{\circ}$ and $90^{\circ}$ to the meridional plane of the instrument (first telescope), and the equivalent intensities at $45^{\circ}$ and $135^{\circ}$ (second telescope). The orthogonal polarization states of the incoming light are spatially separated by a Wollaston prism and measured simultaneously. This approach ensures that the polarization signal is not contaminated by uncorrelated spatial or temporal scene intensity variations during the course of the polarization measurements, which could create "false" polarization.

The instantaneous field of view (14 mrad) is continuously scanned within $\pm 60^{\circ}$ from nadir by a polarizationinsensitive scan mirror system, consisting of two mirrors each used at $45^{\circ}$ angle of incidence and with their planes of incidence oriented orthogonally. This design ensures that the polarization orientation that is perpendicular to the plane of reflection at the first mirror is parallel to the plane of reflection at the second mirror so that all polarization states are transmitted equally. Scanning along-track, the same scene is therefore viewed from multiple angles in successive scans.

In remote sensing applications, it is practical to work with reflectance quantities. The first three components of the Stokes vector I, Q and U, measured by the RSP, are related to dimensionless Bidirectional Reflectance Factors (BRFs, see Appendix A) as follows:

$\mathrm{R}_{\mathrm{I}}=\frac{\pi r_{0}^{2}}{F_{0} \cos \theta_{s}} \mathrm{I}$

$\mathrm{R}_{\mathrm{Q}}=\frac{\pi r_{0}^{2}}{F_{0} \cos \theta_{s}} \mathrm{Q}$

$\mathrm{R}_{\mathrm{U}}=\frac{\pi r_{0}^{2}}{F_{0} \cos \theta_{s}} \mathrm{U}$

where $\theta_{s}$ is the solar zenith angle. The annual average solar flux incident at the top of the atmosphere, $F_{0}$, is 
Table B.1

Absolute error components applying to RSP quantities, with $\mu_{0}$ indicating the cosine of the solar incident angle. The Degree of Linear Polarization (DoLP) is defined as $R_{p} / R_{I}$.

\begin{tabular}{llll}
\hline Quantity & $\sigma_{\text {inst }}$ & $\sigma_{\text {cal }}$ & $\sigma_{\text {pol }}$ \\
\hline $\mathrm{R}_{\mathrm{l}}$ & $\sqrt{10^{-7} \mathrm{R}_{\mathrm{l}} / \mu_{0}}$ & $0.03 \cdot \mathrm{R}_{\mathrm{l}}$ & - \\
$\mathrm{R}_{\mathrm{Q}}$ & $\sqrt{10^{-7} \mathrm{R}_{\mathrm{l}} / \mu_{0}}$ & $0.03 \cdot \mathrm{R}_{\mathrm{Q}}$ & $0.001+0.001 \cdot$ DoLP \\
$\mathrm{R}_{\mathrm{p}}$ & $\sqrt{10^{-7} \mathrm{R}_{\mathrm{l}} / \mu_{0}}$ & $0.03 \cdot \mathrm{R}_{\mathrm{p}}$ & $0.001+0.001 \cdot$ DoLP \\
DoLP & $\sqrt{\frac{10^{-7}}{\mathrm{R}_{\mathrm{l}}\left(1+\mathrm{DoLP}^{2}\right)}}$ & - & $0.001+0.001 \cdot$ DoLP \\
& & & \\
\hline
\end{tabular}

corrected for the Sun-Earth distance $r_{0}$ (in AU) at the time of measurement in order to obtain the proper irradiance.

Three sources of uncertainty affect the measured signal. They are:

- the instrumental noise, limited by shot-noise and depending on $R_{I}$ and incident angle. It is equal for $R_{I}$, $R_{Q}$ and the polarized reflectance $R_{p}=\sqrt{R_{Q^{2}+R_{\mathrm{U}^{2}}}}$. The expression for the Degree of Linear Polarization (DoLP) can be found by error propagation;

- the $3 \%$ uncertainty due to absolute radiometric calibration:

- the uncertainty in the relative polarimetric accuracy, which increases with the degree of linear polarization, yet is maintained within $0.2 \%$ by the RSP internal calibration system measuring orthogonal polarization states.

The choice of polarized reflectance, Q component, or DoLP as a descriptor for the polarization signatures of a specific scene depends on the particular scopes of each analysis, but the DoLP has the clear advantage of being the most accurate measurement since it is not affected by the radiometric calibration error. Table B. 1 reports how the uncertainties described above impact each of these quantities.

\section{Appendix C. The Tuolumne Intrusive Suite}

The flight transect analyzed in this paper intersected the Tuolumne Intrusive Suite, a geologically highly complex area at the eastern margin of the Sierra Nevada Batholith, intruded into marine sedimentary and volcanic rocks [98-100]. The intrusion of the granitic batholith is responsible for the development of intense contact metamorphic processes in the country rock. The geologic framework reflects in the main topographic features, with ridges preferentially aligned NNW-SSE, following the major lithologic contacts. Moving E-W from Mono Lake to North Peak, Paleozoic ( 500-300 Ma) marine metamorphosed rocks are founded in large, isolated bodies (e.g. Mt. Warren), surrounded by granitic and granodioritic rocks (Gilcrest Peak-Mono Dome alignment). To the W, a narrow NNW trending corridor connecting the Tioga Crest to Tioga Peak is underlined by late Paleozoic-early Mesozoic marine sandstone and limestone, and their metamorphic equivalent (marbles). At Saddlebag lake the metamorphosed marine rocks give way to a complex assemblage of Mesozoic volcanics and volcanoclastics, locally highly metamorphosed, that extends up to the eastern slope of Shepherd Crest East. From here to the W, the granitic-granodioritic lithology of Sierra Nevada Batholith dominates almost uninterruptedly. The high elevation of the area together with a long history of glaciations is responsible for the presence of abundant rock debris and talus deposits. Bedrock is primarily exposed on steep cliffs, crests, and in areas of granitic outcrops. The rest of the landscape is covered by scree that can reach several meters of thickness in areas of gentle slope or at the base of hillsides. Valley bottom of major drainages are draped by a variable thickness of glacial deposits (till).

\section{References}

[1] Rodgers C. Inverse methods for atmospheric sounding theory and practice. In: Series on atmospheric, oceanic and planetary physics, vol. 2. World Scientific Publishing Company; 2000.

[2] Roujean J. A bidirectional reflectance model of the Earth's surface for the correction of remote sensing data. J Geophys Res 1992;97(D18):20-455.

[3] Ross I, Ross J. The radiation regime and architecture of plant stands. Springer; 1981.

[4] Li X, Strahler A. Geometric-optical bidirectional reflectance modeling of the discrete crown vegetation canopy: effect of crown shape and mutual shadowing. IEEE Trans Geosci Remote Sens 1992;30(2):276-92.

[5] Lucht W, Hyman A, Strahler A, Barnsley M, Hobson P, Muller J. A comparison of satellite-derived spectral albedos to ground-based broadband albedo measurements modeled to satellite spatial scale for a semidesert landscape. Remote Sens Environ 2000;74(1):85-98.

[6] Wanner W, Li X, Strahler A. On the derivation of kernels for kerneldriven models of bidirectional reflectance. J Geophys Res 1995;100(D10):21077-89.

[7] Lucht W, Schaaf C, Strahler A. An algorithm for the retrieval of albedo from space using semiempirical BRDF models. IEEE Trans Geosci Remote Sens 2000;38(2):977-98.

[8] Luo Y, Trishchenko A, Latifovic R, Li Z. Surface bidirectional reflectance and albedo properties derived using a land coverbased approach with Moderate Resolution Imaging Spectroradiometer observations. J Geophys Res 2005;110(D1).

[9] Strahler A, Muller J, Lucht W, Schaaf C, Tsang T, Gao F, et al. MODIS BRDF/albedo product: algorithm theoretical basis document version 5.0. Technical report. MODIS Science Team; 1999.

[10] Maignan F, Bréon FM, Lacaze R. Bidirectional reflectance of Earth targets: evaluation of analytical models using a large set of spaceborne measurements with emphasis on the Hot Spot Remote Sens Environ 2004;90(2):210-20.

[11] Martonchik J, Diner D, Pinty B, Verstraete M, Myneni R, Knyazikhin $\mathrm{Y}$, et al. Determination of land and ocean reflective, radiative, and biophysical properties using multiangle imaging. IEEE Trans Geosci Remote Sens 1998;36(4):1266-81.

[12] Maignan F, Bréon FM, Fédèle E, Bouvier M. Polarized reflectances of natural surfaces: spaceborne measurements and analytical modeling. Remote Sens Environ 2009;113(12):2642-50.

[13] Waquet F, Léon J, Cairns B, Goloub P, Deuzé J, Auriol F. Analysis of the spectral and angular response of the vegetated surface polarization for the purpose of aerosol remote sensing over land. Appl Opt 2009;48(6):1228-36.

[14] Cairns B, Russell E, Travis L. Research scanning polarimeter: calibration and ground-based measurements. In: Society of photo-optical instrumentation engineers (SPIE) conference series, vol. 3754; 1999. p. 186-96.

[15] Cairns B, Waquet F, Knobelspiesse K, Chowdhary J, Deuzé J. Polarimetric remote sensing of aerosols over land surfaces. Chichester, UK: Springer-Praxis Books in Environmental Sciences; 2009. p. 295-325 [chapter 10].

[16] Hansen J, Travis L. Light scattering in planetary atmospheres. Space Sci Rev 1974;16(4):527-610.

[17] Mishchenko M, Travis L. Satellite retrieval of aerosol properties over the ocean using polarization as well as intensity of reflected sunlight: passive remote sensing of tropospheric aerosol and 
atmospheric corrections from the new generation of satellite sensors. J Geophys Res 1997;102(D14):16989-7013.

[18] Herman M, Vanderbilt V. Polarimetric observations in the solar spectrum for remote sensing purposes. Remote Sens Rev 1997;15(1):35-57.

[19] Mishchenko M, Cairns B, Chowdhary J, Geogdzhayev I, Liu L, Travis L. Remote sensing of terrestrial tropospheric aerosols from aircraft and satellites. In: Journal of physics conference series, vol. 6; 2005. p. 73-89.

[20] Van De Hulst $H$. Light scattering by small particles. Dover Publications; 1957.

[21] Hovenier J. Symmetry relationships for scattering of polarized light in a slab of randomly oriented particles. J Atmos Sci 1969; 26(3):488-99.

[22] Chowdhary J, Cairns B, Mishchenko M, Hobbs P, Cota G, Redemann $\mathrm{J}$, et al. Retrieval of aerosol scattering and absorption properties from photopolarimetric observations over the ocean during the CLAMS experiment. J Atmos Sci 2005;62(4):1093-117.

[23] Aoki T, Aoki T, Fukabori M. Path-radiance correction by polarization observation of sun glint glitter for remote measurements of tropospheric greenhouse gases. Appl Opt 2002;41:4945-57.

[24] Ottaviani M, Stamnes K, Koskulics J, Eide H, Long S, Su W, et al. Light reflection from water waves: suitable setup for a polarimetric investigation under controlled laboratory conditions. J Atmos Oceanic Technol 2008;25(5):715-28.

[25] Cox C, Munk W. Measurement of the roughness of the sea surface from photographs of the Sun's glitter. J Opt Soc Am 1954;44(11): 838-50.

[26] Rondeaux G, Herman M. Polarization of light reflected by crop canopies. Remote Sens Environ 1991;38(1):63-75.

[27] Vanderbilt VCV, Grant L. Plant canopy specular reflectance model. IEEE Trans Geosci Remote Sens 1985;23:722-30.

[28] Brèon F-M, Tanrè D, Lecomte P, Herman M. Polarized reflectance of bare soils and vegetation: measurements and models. IEEE Trans Geosci Remote Sens 1995;33(2):487-99.

[29] Born M, Wolf E. Principles of optics. 7th (expanded) edCambridge University Press; 1999.

[30] Nadal F, Bréon FM. Parameterization of surface polarized reflectance derived from POLDER spaceborne measurements. IEEE Trans Geosci Remote Sens 1999;37(3):1709-18.

[31] Pollack J, Toon O, Khare B. Surface refractive index. Icarus 1973;19:372-89.

[32] Curran P. Polarized visible light as an aid to vegetation classification. Remote Sens Environ 1982;12(6):491-9.

[33] Shibayama M, Watanabe Y. Estimating the mean leaf inclination angle of wheat canopies using reflected polarized light. Plant Prod Sci 2007;10(3):329-42.

[34] Tang S, Chen J, Zhu Q, Li X, Chen M, Sun R, et al. Lai inversion algorithm based on directional reflectance kernels. J Environ Manage 2007;85(3):638-48.

[35] Curran P. The relationship between polarized visible light and vegetation amount. Remote Sens Environ 1981;11:87-92.

[36] Leroy M, Deuzé JL, Bréon FM, Hautecoeur O, Herman M, Buriez JC, et al. Retrieval of atmospheric properties and surface bidirectional reflectances over land from POLDER/ADEOS. J Geophys Res 1997;102(D14):17023-37.

[37] Spurr R. VLIDORT: a linearized pseudo-spherical vector discrete ordinate radiative transfer code for forward model and retrieval studies in multilayer multiple scattering media. J Quant Spectrosc Radiat Transfer 2006;102(2):316-42.

[38] Spurr R. LIDORT and VLIDORT: linearized pseudo-spherical scalar and vector discrete ordinate radiative transfer models for use in remote sensing retrieval problems. Light Scattering Rev 2008;3: 229-75.

[39] Hasekamp O, Landgraf J. Linearization of vector radiative transfer with respect to aerosol properties and its use in satellite remote sensing. J Geophys Res 2005;110 D04203-.

[40] Spurr R. A new approach to the retrieval of surface properties from earthshine measurements. J Quant Spectrosc Radiat Transfer 2004;83(1):15-46.

[41] Landgraf J, Hasekamp O, Trautmann T. Linearization of radiative transfer with respect to surface properties. J Quant Spectrosc Radiat Transfer 2002;72(4):327-39.

[42] Walter H, Landgraf J. Towards linearization of atmospheric radiative transfer in spherical geometry. J Quant Spectrosc Radiat Transfer 2005;95(2):175-200.

[43] Spurr RJD. Simultaneous derivation of intensities and weighting functions in a general pseudo-spherical discrete ordinate radiative transfer treatment. J Quant Spectrosc Radiat Transfer 2002;75(2): 129-75.

[44] Wang Y, Yang C, Li X. A regularizing kernel-based BRDF model inversion method for ill-posed land surface parameter retrieval using smoothness constraint. J Geophys Res 2008;113(D13) D13101-

[45] Markwardt CB. Non-linear least-squares fitting in IDL with MPFIT. In: Bohlender DA, Durand D, Dowler P, editors. Astronomical data analysis software and systems XVIII, Astronomical society of the pacific conference series, vol. 411; 2009. p. 251-.

[46] Zaveri RA, Shaw WJ, Cziczo DJ, Schmid B, Ferrare RA, Alexander ML, et al. Overview of the 2010 carbonaceous aerosols and radiative effects study (CARES). Atmos Chem Phys Discuss 2012;12(1):1299-400. http://dx.doi.org/10.5194/acpd-12-1299-2012.

[47] Waquet F, Cairns B, Knobelspiesse K, Chowdhary J, Travis L, Schmid B, et al. Polarimetric remote sensing of aerosols over land. J Geophys Res Atmos 2009;114(D1) D01206-.

[48] Hair J, Hostetler C, Cook A, Harper D, Ferrare R, Mack T, et al. Airborne high spectral resolution lidar for profiling aerosol optical properties. Appl Opt 2008;47(36):6734-52.

[49] Dozier J, Painter T. Multispectral and hyperspectral remote sensing of alpine snow properties. Annu Rev Earth Planet Sci 2004;32: 465-94.

[50] Dozier J, Green R, Nolin A, Painter T. Interpretation of snow properties from imaging spectrometry. Remote Sens Environ 2009;113:S25-37.

[51] Painter TH, Duval B, Thomas WH, Mendez M, Heintzelman S, Dozier J. Detection and quantification of snow algae with an airborne imaging spectrometer. Appl Environ Microbiol 2001;67(11): 5267-72. http://dx.doi.org/10.1128/AEM.67.11.5267-5272.2001.

[52] Nakaya U. Snow crystals, natural and artificial. Harvard University Press; 1954

[53] Libbrecht K. The physics of snow crystals. Rep Prog Phys 2005;68: 855-95.

[54] Grenfell T, Perovich John A, Donald K. Spectral albedos of an alpine snowpack. Cold Reg Sci Technol 1981;4(2):121-7.

[55] Painter T, Dozier J, Roberts D, Davis R, Green R. Retrieval of subpixel snow-covered area and grain size from imaging spectrometer data. Remote Sens Environ 2003;85(1):64-77.

[56] Grenfell T, Warren S, Mullen P. Reflection of solar radiation by the Antarctic snow surface at ultraviolet, and near-infrared wavelengths. J Geophys Res 1994;99(18):618-69.

[57] Stamnes K, Li W, Eide H, Aoki T, Hori M, Storvold R. ADEOS-II/GLI snow/ice products-part I: scientific basis. Remote Sens Environ 2007:111(2-3):258-73.

[58] Zege E, Katsev I, Malinka A, Prikhach A, Polonsky I. New algorithm to retrieve the effective snow grain size and pollution amount from satellite data. Ann Glaciol 2008;49(1):139-44.

[59] Painter T, Rittger K, McKenzie C, Slaughter P, Davis R, Dozier J. Retrieval of subpixel snow covered area, and albedo from MODIS. Remote Sens Environ 2009;113(4):868-79.

[60] Peltoniemi JI, Suomalainen J, Hakala T, Näränen J, Puttonen E, Kaasalainen S, et al. Reflectance of various snow types: measurements, modeling, and potential for snow melt monitoring. In: Kokhanovsky AA, editor. Light scattering reviews, springer praxis books, vol. 5. Berlin, Heidelberg: Springer; 2010. p. 393-449 [ISBN 978-3-642-10336-0, chapter 9].

[61] Green R, Painter T, Roberts D, Dozier J. Measuring the expressed abundance of the three phases of water with an imaging spectrometer over melting snow. Water Resour Res 2006;42(10) 10402-

[62] Peltoniemi J, Kaasalainen S, Naranen J, Matikainen L, Piironen J. Measurement of directional and spectral signatures of light reflectance by snow. IEEE Trans Geosci Remote Sens 2005;43(10): 2294-304.

[63] Nolin AW, Frei A. Remote sensing of snow and characterization of snow albedo for climate simulations. In: Beniston M, Verstraete MM editors. Remote sensing and climate modeling: synergies and limitations. Advances in global change research, vol. 7. Netherlands: Springer; 2003. p. 159-80 [ISBN 978-0-306-48149-9]

[64] Hansen J, Nazarenko L. Soot climate forcing via snow and ice albedos. Proc Nat Acad Sci USA 2004;101(2):423-8.

[65] Wiscombe W, Warren S. A model for the spectral albedo of snow. I: pure snow. J Atmos Sci 1980;37(12):2712-33.

[66] Warren S, Wiscombe W. A model for the spectral albedo of snow. II: snow containing atmospheric aerosols. J Atmos Sci 1980; 37(12):2734-45.

[67] Perovich D. Theoretical estimates of light reflection and transmission by spatially complex and temporally varying sea ice covers. J Geophys Res 1990;95(C6):9557-67. 
[68] Mishchenko M, Dlugach J, Yanovitskij E, Zakharova N. Bidirectional reflectance of flat, optically thick particulate layers: an efficient radiative transfer solution and applications to snow and soil surfaces. J Quant Spectrosc Radiat Transfer 1999;63(2-6): 409-32.

[69] Aoki T, Aoki T, Fukabori M, Hachikubo A, Tachibana Y, Nishio F. Effects of snow physical parameters on spectral albedo and bidirectional reflectance of snow surface. J Geophys Res 2000;105(D8):10219-36.

[70] Kokhanovsky A, Zege E. Scattering optics of snow. Appl Opt 2004;43(7):1589-602.

[71] Brandt RE, Warren SG, Worby AP, Grenfell TC. Surface albedo of the antarctic sea ice zone. J Clim 2005;18(17):3606-22, http://dx.doi.org/10.1175/JCLI3489.1.

[72] Jin Z, Charlock T, Yang P, Xie Y, Miller W. Snow optical properties for different particle shapes with application to snow grain size retrieval and MODIS/CERES radiance comparison over Antarctica. Remote Sens Environ 2008;112(9):3563-81.

[73] Kuipers Munneke P, Reijmer C, van den Broeke M, König-Langlo G, Stammes P, Knap W. Analysis of clear-sky Antarctic snow albedo using observations and radiative transfer modeling. J Geophys Res 2008;113 D17118-.

[74] Leroux C, Lenoble J, Brogniez G, Hovenier J, DE H, et al. A model for the bidirectional polarized reflectance of snow. J Quant Spectrosc Radiat Transfer 1999;61(3):273-85.

[75] Peltoniemi J. Spectropolarised ray-tracing simulations in densely packed particulate medium. J Quant Spectrosc Radiat Transfer 2007;108(2):180-96.

[76] Leroux C, Deuzé J, Goloub P, Sergent C, Fily M. Ground measurements of the polarized bidirectional reflectance of snow in the near-infrared spectral domain: comparisons with model results. J Geophys Res 1998;103(D16):19721-31.

[77] Mondet J, Fily $M$. The reflectance of rough snow surfaces in Antarctica from POLDER/ADEOS remote sensing data. Geophys Res Lett 1999;26(23):3477-80.

[78] Peltoniemi J, Hakala T, Suomalainen J, Puttonen E. Polarised bidirectional reflectance factor measurements from soil, and snow. J Quant Spectrosc Radiat Transfer 2009;110(17):1940-53. http://dx.doi.org/ 10.1016/j.jqsrt.2009.04.008.

[79] Sun Z, Zhao Y. The effects of grain size on bidirectional polarized reflectance factor measurements of snow. J Quant Spectrosc Radiat Transfer 2011;112(14):2372-83 http://dx.doi.org/10.1016/j.jqsrt.2011. 05.011.

[80] Gao B, Kaufman Y. Water vapor retrievals using Moderate Resolution Imaging Spectroradiometer (MODIS) near-infrared channels. J Geophys Res 2003;108(D13) 4389-.

[81] Ottaviani M, Cairns B, Chowdhary J, Van Diedenhoven B, Knobelspiesse $\mathrm{K}$, Hostetler $\mathrm{C}$, et al. Polarimetric retrievals of surface and cirrus clouds properties in the region affected by the Deepwater Horizon oil spill. Remote Sens Environ 2012;121(0):389-403.

[82] Halthore R, Eck T, Holben B, Markham B. Sun photometric measurements of atmospheric water vapor column abundance in the 940-nm band. J Geophys Res 1997;102(D4):4343-52.

[83] Segelstein D. The complex refractive index of water. PhD thesis. Department of Physics, University of Missouri-Kansas City; 1981.
[84] Warren S, Brandt R. Optical constants of ice from the ultraviolet to the microwave: a revised compilation. J Geophys Res 2008;113 D14220-.

[85] Veefkind J, de Haan J, Brinksma E, Kroon M, Levelt P. Total ozone from the Ozone Monitoring Instrument using the DOAS technique. IEEE Trans Geosci Remote Sens 2006;44(5):1239-44.

[86] Lewis P. The utility of kernel-driven BRDF models in global BRDF and albedo studies. In: Geoscience and remote sensing symposium, 1995 IGARSS'95. Quantitative remote sensing for science and applications, international, vol. 2. IEEE; 2002. p. 1186-8. ISBN 0780325672.

[87] Dubovik O, King M. A flexible inversion algorithm for retrieval of aerosol optical properties from Sun and sky radiance measurements. J Geophys Res 2000;105(D16):20673-96.

[88] Litvinov P, Hasekamp O, Cairns B, Mishchenko M. Reflection models for soil and vegetation surfaces from multiple-viewing angle photopolarimetric measurements. J Quant Spectrosc Radiat Transfer 2010;111(4):529-39.

[89] Lyapustin A, Gatebe C, Kahn R, Brandt R, Redemann J, Russell P, et al. Analysis of snow bidirectional reflectance from ARCTAS Spring-2008 Campaign. Atmos Chem Phys 2010;10:4359-75.

[90] Deuzé J, Bréon FM, Devaux C, Goloub P, Herman M, Lafrance B, et al. Remote sensing of aerosols over land surfaces from POLDERADEOS-1 polarized measurements. J Geophys Res 2001;105: 4913-26.

[91] Macke A, Mueller J, Raschke E. Single scattering properties of atmospheric ice crystals. J Atmos Sci 1996;53(19):2813-25.

[92] Grenfell T, Warren S. Representation of a nonspherical ice particle by a collection of independent spheres for scattering and absorption of radiation. J Geophys Res 1999;104(D24):31697-709.

[93] Neshyba S, Grenfell T, Warren S. Representation of a nonspherical ice particle by a collection of independent spheres for scattering and absorption of radiation: 2. Hexagonal columns and plates. J Geophys Res 2003;108(10.1029).

[94] Grenfell T, Neshyba S, Warren S. Representation of a nonspherical ice particle by a collection of independent spheres for scattering and absorption of radiation: 3. Hollow columns and plates. J Geophys Res 2005;110 D17203-.

[95] Nicodemus F, Richmond J, Hsia J, Ginsberg I, Limperis T. Geometrical considerations and nomenclature for reflectance. Technical report. U.S. Department Of Commerce, National Bureau of Standards; 1977.

[96] Schaepman-Strub G, Schaepman M, Painter T, Dangel S, Martonchik J. Reflectance quantities in optical remote sensingdefinitions and case studies. Remote Sens Environ 2006;103(1): 27-42.

[97] Thomas G, Stamnes K. Radiative transfer in the atmosphere and ocean. Cambridge University Press; 2002.

[98] Bateman P, Chappell B. Crystallization, fractionation, and solidification of the Tuolumne intrusive series, Yosemite National Park California. Bull Geol Soc Am 1979;90(5) 465-.

[99] Kistler R, Chappell B, Peck D, Bateman P. Isotopic variation in the Tuolumne intrusive suite, central Sierra Nevada, California. Contrib Mineral Petrol 1986;94(2):205-20.

[100] Bateman P. Plutonism in the central part of the Sierra Nevada batholith, California. US Geol survey professional paper 1483; 1992. 